\title{
THE INFLUENCE OF WORK PLACEMENT ON THE ACADEMIC ACHIEVEMENT OF UNDERGRADUATE DESIGN STUDENTS
}

\begin{abstract}
The aim of this paper is to investigate the contribution of work placement in enhancing the academic performance of undergraduate design students. A statistical analysis was carried out on a population sample which comprised design students who had graduated at Brunel University London in four different academic years. All the required (anonymous) data were obtained from the university electronic records system. The dataset comprises a total of 411 students, of which 323 were placement students and 88 non-placement students. Students were also classified as higher achievers (students whose second year average mark was $60 \%$ or above) and lower achievers. The results seem to suggest that for both higher and lower achievers the placement experience enables students to achieve on average a greater final year mark and a greater improvement from the second to the final year. The study also established that these grade gains were of a similar magnitude irrespective of the students overall academic standing. Finally, the results of this study seem to suggest that the work placement experience give students a particular advantage in the final year project and in the modules characterized by design-focused assessment components.
\end{abstract}

Keywords: Work placement, Design Education, Academic achievement, Academic performance, Undergraduate students.

\section{INTRODUCTION}

The United Kingdom Government is strongly supporting the strengthening of relationships between education and industry (Department for Business Education \& Skills, 2012). The business-university collaboration is considered crucial to maximise the contribution of universities to local economic growth (ibid.). In particular, work placements are acknowledged to bring about great benefits to students and businesses, because they can better prepare graduates for the world of work (ibid.). In 1997, the Dearing report on Higher Education suggested that all institutions should increase placement programmes to help students to become familiar with the world of work. The UK Government's Department for Education and Skills, in their White Paper on Higher 
Education (2003), reiterated this concept and highlighted the crucial role that higher education in producing a high quality graduate workforce.

Several studies have investigated the benefits that students can get from work placement. These benefits can be grouped in increased employability and better academic achievements. Regarding employability, it has been suggested that doing a work placement makes graduates more likely to gain employment (Blackwell et al., 2001; Greenbank, 2002; Blasko et al., 2002). This is linked to the fact that students can enhance their transferable skills during work placements (Greenbank, 2002; Neil et al., 2004; Little and Harvey, 2006; Lucas and Tang, 2007). And these transferable skills, such as communication, team working and time management, are considered very important by employers (Muhamad, 2012). Other studies also show that doing a work placement increases the opportunities to progress more quickly and get higher salaries early on in their careers (Mason et al., 2003; Little and Harvey, 2004). In addition, Neill and Mulholland (2003) and Walmsley et al. (2006) have investigated students' perceptions on work placement experience, and they found that students believe work placements have improved their transferable skills and helped them to better link theory to practice.

If the connection between work placement and increased employability is clearly supported by evidence, the same cannot be said between work placement and higher academic achievements. Some qualitative studies propose that students who go on placement are better prepared to face the challenges of their final year (Auburn, 2007). As suggested by Patel et al. (2012), three main reasons can be identified to explain this. First, a placement experience enables students to improve transferable skills, which in turn can be used to better cope with their final year requirements (Reddy and Moore, 2006). Second, students who make 'real world' experiences can better connect theory to practice and vice versa (Morgan, 2007). And third, students who went on placement show an increased maturity and motivation (Morgan and Turner, 2000., Rakowski, 1990).

However, there are only a few quantitative studies which explored the relationship between work placement and academic achievement and, interestingly, the results of these studies are not consistent.

Most of the studies show that students undertaking a work placement achieve higher final year marks than non-placement students (Mandileras, 2004; Gomez et al., 2004; Rawling et al., 2005; Reddy and Moores, 2006; Mendez, 2008; Surridge, 2009; Bullock et al., 2009; Patel et al., 2012). With the exception of Bullock et al. (2009), whose research focused on engineering and bioscience students, all the other studies investigated the phenomenon within a single programme of study: in particular 
Mandileras (2004) focused on economics students, Gomez et al. (2004) on bioscience students, Rawling et al. (2005) on information systems students, Mendez (2008) on engineering students, Surridge (2009) on business students, and Patel et al. (2012) on computing students. The research undertaken by Reddy and Moore (2012) was the first to analyse data from a range of different programmes and, consequently, from a relative big sample size (around 6000). The results of this study also show the positive correlation between work placement and academic achievements in the final year. However, in contrast with these findings, Duignan $(2002,2003)$ found that there is not a significant difference in academic achievements between the business students who went on placement and the ones who did not.

Analysing the results of the existing studies, it is possible to say that there is strong evidence that students who go on placement can get a higher degree classification. However, does this mean that placement experience equips students to better deal with their final year? Or does this mean that students who go on placement are simply better than students who do not?

Even in relation to this aspect, existing studies provide contradictory results. Reddy and Moores (2006) found that human psychology students who went on placement had higher grades in their second year compared to students who did not go, and thus it was expected they would have achieved higher grades in their third year. The research undertaken by Bullock et al. (2009) also supports the assertion that students who go on placement tend to be the more capable ones. Interestingly, they also found that the improvement in the average mark (from the second to the final year) was higher for non-placement engineering students. In other words, even if non-placement engineering students achieved lower grades in their final year, they were able to improve more than placement students. However, for bioscience students, they found the opposite: students who went on placement obtained a greater improvement in their final year marks compared to non-placement students.

Some other studies seem to support the hypothesis that gaining placement experience provides added value in terms of final year academic achievements. Rawling et al. (2005) showed that there is strong statistical evidence to say that students with the same second year average marks achieved a higher degree classification if they went on placement. In line with these results, Surridge (2009) found that there was no significant difference in academic performance of business students going on placement and those continuing on full-time courses, and that students who go on placement achieve significantly better final-year marks (3.6\% higher). Gomez et al. (2004) found that there is a demonstrable improvement of bioscience students' final year marks that is independent from first and second year measures of performance. The analysis made 
by Patel et al. (2012) also provided no support for the hypothesis that placement students better perform in their final year because they have higher academic performances to begin with.

It is also important to highlight that the relationship between work placement and academic achievements in design programmes is under-researched. No quantitative study has been carried out on this topic. As pointed out by Reddy and Moore (2012), for some programmes the skills and experience gained during placement can be of more direct benefit. It is expected that this is the case for design programmes. Design is in fact a skills-based discipline that cannot be learned without practical applications. It is not possible to become a designer without applying skills and knowledge in practice. For this reason design programmes are often built around 'Design Process' modules, where students have to tackle design challenges. In addition, it is very common that in their other modules students are required to carry out some design activities, to apply in practice what they learned. Since learning by doing is the core of design pedagogy, it is expected that students who have a 'real world' experience in a company or a design consultancy would be better equipped to face the requirements of their final year. In particular, it is expected that they would perform better in their Major Project and in the modules characterized by a strong design component.

To summarize, the key issues that emerged from the literature review are as follows. First, results of existing studies are inconsistent. And second, no quantitative study has been carried out on design programmes. Therefore it seems promising to investigate how doing a work placement influences final year academic achievements in design programmes. In particular, the research questions addressed in this study are:

- Do design students who undertake a work placement achieve higher academic performance in their final year?

- If yes, is it because they are better than non-placement students or because the placement experience provides an added value to them?

- If work placement provides an added value to students in terms of academic performance in their final year, is this true for all the modules or only for some particular ones?

These research questions are tackled by statistically analysing the academic performance of placement and non-placement students studying design at Brunel University. In order to increase the sample population and limit the risk of selecting an atypical year, the study combines data over four consecutive graduation years.

The paper is structured as follows. Firstly, the paper describes the structure of the work placement in the design programmes offered by Brunel University London. The paper 
then illustrates the method used to collect the data and continues by presenting and discussing the results of the analysis. The paper then provides a reflection on the practical implications of the findings, and concludes by discussing the limitation of the study and highlighting directions for future research.

\section{WORK PLACEMENT AT BRUNEL DESIGN}

Brunel Design offers three Undergraduate Programmes: BSC Product Design, BSC Product Design Engineering and BA Industrial Design and Technology. The three programmes offer some common core modules (80 credits at Level 1 and 2, and 60 credits at Level 3) and some specialist modules. At Level 3 students have also the option to choose from a set of elective modules.

For each of the three programmes students can select a full-time 3-year programme or a four year 'thick-sandwich' degree with one year industry placement. The placement is undertaken after the successful completion of the second year of study and has a minimum duration of 44 weeks. During the placement, an academic tutor visits the placement company at least twice to ensure adequate support and personal development opportunities are available. On successful completion the degree award will have 'with Professional Practice' added to the programme title.

The summative assessment methods that enable students to demonstrate the work placement learning outcomes are currently as follows:

- Portfolio of Evidence (40\%) comprising a personal development plan where the students set out their own learning goals and objectives for the placement,

- Professional Practice Report (60\%), where students reflect on their learning experience and outcomes over the duration of the placement.

\section{DATA COLLECTION}

The statistical analysis was carried out on a sample group which comprised students who had graduated in one of the three Brunel Design programmes in the 2010/11, 2011/12, 2012/13, and 2013/14 academic years (Figure 1). It was decided to include four academic years in the analysis in order to increase the sample population and limit the risk of selecting an atypical year.

All the required (anonymous) data were obtained from the University Taught Programme Office electronic records system. The dataset comprises a total of 411 students, of which 323 were placement students and 88 non-placement students. Records contained 
information on: degree programme, degree classification, final year average mark, second year average mark, first year average mark, single marks achieved in all the modules, and whether or not the student took the placement.

Figure 1. The data considered in the analysis comprises students who had graduated in one of the three Brunel Design programmes in the 2010/11, 2011/12, 2012/13 and 2013/14 academic years.

\section{ANALYSIS AND DISCUSSION OF FINDINGS}

\subsection{COMPARISON OF FINAL YEAR RESULTS}

The first step of the analysis focused on understanding whether students who undertook a work placement achieved higher academic performance in their final year. Differing from some studies (e.g. Patel et al. 2012) this analysis did not compare the overall degree classification awarded because this would incorporate an $8.3 \%$ contribution to the degree class based on the placement module assessment. Rather, the analysis compared the average mark achieved by placement and non-placement students in all the final year modules only.

The results show that design students who went on placement achieved a higher final year average $(66.7 \%$ vs $59.6 \%)$, see Figure 2 . The T-test analysis confirms that these results are statistically significant $\left(p=4 \times 10^{-15}\right)$. The same comparison was conducted considering only the final year modules common to all the three programmes: similar results have been found (64.7 for placement students vs 57.5 for non-placement students, $\left.p=6 \times 10^{-15}\right)$. As expected, the averages for common modules are lower than the averages for all the modules. This is due to the fact that students in their final year can personalize their study plan by selecting a combination of optional modules. These modules are often chosen on the basis of students' personal interest, and therefore students' performance in these modules is usually higher than in compulsory (core) modules.

Figure 2. Comparison of final year academic achievements of placement and non-placement students considering the average mark of all modules and the average mark of only the common modules. 
In line with most of the studies mentioned earlier, it was found that students who complete a work placement achieve higher academic performance in their final year. However, this does not tell if it is because the placement experience better equips students to deal with their final year or simply because students who go on placement are better academically than students who do not. To understand this it is needed to compare and analyse Level 2 averages and in particular the average mark improvement between Level 2 and Level 3.

\subsection{COMPARISON OF SECOND YEAR RESULTS AND IMPROVEMENT BETWEEN SECOND AND FINAL YEAR}

Looking at the students academic achievements in the second year (prior to placement), the analysis clearly shows that students who go on placement tend to be better academically with an overall mark average higher than non-placement students $(64.1 \%$ vs $\left.58.1 \%, p=4 \times 10^{-15}\right)$, see Figure 3 . These results, in line with that found by Reddy and Moores (2006) and Bullock et al. (2012), support the statement that students who go on work placement are, at Level 2, academically more capable than students who do not go. However, it is important to highlight that the data taken into consideration for the second year results are obtained across two different academic years (e.g. considering the students who graduated in 2013/14, placement students did their Level 2 in 2011/12 while non-placement students in 2012/13) (see Figure 1). This means that, within each programme, placement and non-placement students attended the same Level 2 modules but in different academic years. Thus, lectures, learning resources, assessment criteria and assessment modalities may have changed. It is worth noting that whilst staffing and projects may have varied across the measurement period, there was no significant change to the curriculum. It is hoped by analysing student results over an extended period (four academic years), that minor delivery variations should have negligible impact on the results of this study.

Figure 3. Comparison of Level 2 academic achievements of placement and non-placement students.

Although results show that students who go on placement are academically better than students who do not go, will the placement experience still add value to student's marks in their final year? To investigate this issue a comparison between the average mark obtained at Level 2 and the average mark obtained in the final year was carried out. 
This comparison shows that placement students improved on average by $2.6 \%$ points, while non-placement students by $1.5 \%$ points (Figure 4 ). Thus, placement students show greater improvement in the final year. However, a T-test was performed on these results, showing that this difference is not statistically significant $(p=0.10)$. This seems to support Duignan's findings (Duignan, 2002; 2003), who argues that there is not a significant difference in academic achievements between the students who went on placement and the ones who did not, and so that the placement experience does not enable students to better perform in their final year.

Figure 4. Comparison of the academic performance improvements (from Level 2 to the final year) of placement and non-placement students.

To summarize, at this stage of the study, findings suggest that students who go on placement achieved a higher average mark in their final year because they have a higher academic performance to begin with, and that the placement experience does not provide any advantage in terms of academic achievements. This contradicts the findings of Rakowski (1990), which indicates that students on placement have additional incentives to perform to a higher standard whilst working. Does the improvement in professional conduct and performance in real-life work situations act as a stimulus and motivation for continued high performance on a daily basis on their return to university? To investigate this point, students were better differentiated. Following the strategy adopted by Reddy and Moores (2006) students were classified in two groups:

- higher achievers: students whose second year average mark was $60 \%$ or above

- lower achievers: students who whose second year average mark was less than $60 \%$

This differentiation allows to better investigating the influence that work placement produces on students with different academic performances. For these two groups the average marks in the final year and in the second year, and the improvement from the second to the final year were compared.

Some interesting results came out from this comparison, see Figure 5.

Figure 5. Comparison of the academic performance improvements (from Level 2 to the final year) of placement and non-placement students, differentiating them in higher achievers (students whose 
second year average mark was $60 \%$ or above) and lower achievers (students who whose second year average mark was less than 60\%).

Let us start by analysing higher achievers. Higher achievers who went on placement had an overall mark average at Level 2 similar to non-placement students. There is a difference $(66.7 \%$ vs $66.3 \%)$ but this has been found to be not statistically significant $(p=0.46)$. So, at the end of Level 2 , there is no significant difference in the academic performance of the students who went on placement compared to ones who did not go. However, what is interesting to note is the difference in their academic performance in the final year. Higher achievers who went on placement were able to obtain an average mark of $68.1 \%$ (with an improvement of $1.3 \%$ points), while non-placement students achieved an average mark of $64.4 \%$ (with a worsening of $1.9 \%$ points). A T-test analysis showed that these results are statistically significant $\left(p=2 \times 10^{-4}\right)$. These results clearly suggest that the work placement is beneficial for higher achievers, enabling them to slightly increase their average. On the other hand, higher achievers who do not take the work placement tend not to maintain the same academic standard and their average grade is more likely to worsen.

Looking at lower achievers, results show that both placement and non-placement students improved their average mark in the final year. However, placement students were able to obtain a more substantial improvement (from $55.6 \%$ to $62.2 \%$ with a $6.6 \%$ points improvement) compared to non-placement students (from $53.4 \%$ to $56.8 \%$ with a $3.4 \%$ improvement). These results suggest that the placement experience is more beneficial for lower achievers. As shown by the data, they can move to the higher achievers average mark range and get closer to the academic achievements obtained by non-placement higher achievers. However, a certain degree of caution must be taken because the Level 2 average marks for placement and non-placement students show a substantial difference $(55.6 \%$ vs $53.4 \%$, with $p=0.007)$. This means that, by contrast from what was found for higher achievers, lower achievers who go on placement are academically better than non-placement students. This must be taken into account because it might represent a factor contributing to the greater improvement of placement students in the final year. However, with placement students who are academically more capable, this fact alone cannot explain their higher improvement $(+6.5 \%)$ in their final year, and therefore that the placement experience is beneficial for them.

In summary, results show that both higher and lower achiever students who complete a work placement obtain higher academic performance in their final year. 


\subsection{COMPARISON OF INDIVIDUAL MODULES}

In their final year, all students (both placement and non-placement) must take the Major Project (40 cp module) and the Innovation Management $20 \mathrm{cp}$ module. In addition to these core modules there are some additional compulsory modules (depending on the specific design programme) and some optional modules. Some of these modules are characterized by a strong practical design component while some others are predominantly theoretical. The hypothesis is that students who had a 'real world' experience in a company or a design consultancy should be better equipped to achieve higher marks in the modules characterized by design-focused assessment components. In order to verify this hypothesis four such modules were selected. In addition to the two core modules previously mentioned, the analysis included the modules that are selected by at least $75 \%$ of the students (otherwise the sample would be too small to obtain statistically significant results), and that can be taken by students enrolled on any of the design programmes. Modules are considered predominantly theoretical if more than $50 \%$ of the mark comes from assignments which do not focus on design tasks/activities. The selected modules are:

- Major Project: core module, where students are required to take a design project independently;

- Innovation Management: core module, predominantly focused on design;

- Contextual Design: optional module, predominantly focused on design;

- Environmentally Sensitive Design: optional module, predominantly theoretical.

Comparing the results of each individual module supports the hypothesis (Figure 6). In fact it was found that, for the modules predominantly focused on design, the work placement experience had a positive influence: both higher and lower achievers who went on placement obtained a higher mark than non-placement students. It is, in particular, interesting to look at the results of the Major Project and Innovation Management modules: lower achievers who went on placement were able to close the gap with the higher achievers who did not go on placement (obtaining a similar mark).

On the other hand, the results on the Environmentally Sensitive Design module (predominantly theoretical) show that the placement experience does not have any influence on attainment in this module: the differences in the average marks are in fact not statistically significant $(69.7 \%$ vs $69.1 \%$ with $p=0.75$ for placement students, and $64.5 \%$ vs $61.5 \%$ with $p=0.12$ for non-placement students).

Thus, results suggest that the transferrable skills that students gain during their placement (i.e. enhanced design skills, organisation and time management, written and oral communication, self-confidence, ability to work independently, etc. (Neil and 
Mulholland, 2003)) are used by students in the Major project and in all the assessment components focused on a specific design task, and this provides an advantage to them in comparison to non-placement students.

Figure 6. Comparison of the academic performance of placement and non-placement students (differentiating them in higher achievers and lower achievers) in four different final year modules. The first three modules are considered predominantly focused on design, while the fourth is considered predominantly theoretical.

However, care must be taken in analysing these results, for three main reasons. Firstly, in some of the modules there are group assignments and same groups may have both placement and non-placement students, however, it is important to highlight that in all group assessments there is always an individual assessment component. Secondly, some assessment components might blend design tasks with theoretical elements. And thirdly, there is no final year module characterized by being completely theoretical: all the modules, including Environmentally Sensitive Design, have at least one assessment component focused on design. In this regard, it would be useful to analyse the results of each assessment component in order to separate design assessment components from theoretical assessment components.

\section{PRACTICAL IMPLICATIONS}

The results of this study can be used as a starting point to improve the overall quality of design programmes. Two main aspects have been identified:

The first consideration is that these findings, in line with what is suggested by Patel et al. (2012), can be used to encourage students to opt for sandwich programmes. These results can in fact be used by departmental placement officers for promoting placement and attract student interest. The positive effect of the placement experience in enhancing employability has been widely documented (e.g. Blackwell et al., 2001; Greenbank, 2002; Blasko et al., 2002). However, this is the first study, specifically focused on design students, which shows the beneficial contribution that work placement has on academic achievement. Therefore, the combination of increased employability and better final year results can be used by placement officers as an argument to more effectively encourage students in taking a work placement experience. Brunel Design is already performing very well on this regard: in the 2013-2014 academic year more than $80 \%$ of the students went on placement and the number of students who wanted to go 
on placement was higher than the available offers. Additionally, these results may encourage other universities in better promoting and supporting sandwich programmes in the design subject area. The advantages are in fact not only for the students but also for the universities, in terms of reputation and opportunity to build up strategic links with companies and design consultancies.

The second consideration is about the integration of placement and non-placement students in their final year. In the last few years, several fast-track students have reported to the final year tutor or their personal tutor that they had been facing difficulties in integrating with the other returning students. As previously mentioned most of the final year students go on placement. Thus, fast trackers do not usually know many students in the final year because most of their Level 2 friends go on placement when they enter into Level 3. Another reason contributing to their integration problem is that they are judged, by the returning students, as less capable than placement students. Students who went on placement gained an enhanced set of skills, including design acumen, written and oral communication, time management, selfconfidence, ability to work independently, etc., that may not yet be fully developed in fast trackers. For these two reasons, when students have to form groups (to work on summative or formative assessments), fast trackers struggle to get into a team with non-fast track students. It is therefore crucial to create the conditions to foster the interaction between fast trackers and placement students. Working in teams with students who went on placement might in fact support fast trackers in gaining, at least to a certain extent, some of the previously mentioned transferrable skills. Also, as suggested by the findings of this study, if students gain these skills they are more likely to improve their academic performance. Some strategies to foster interaction between the two groups may be to: (a) make it compulsory that work teams must have at least one fast tracker student, and (b) organize social events in the first weeks of term 1 to allow fast trackers and placement students to get to know each other.

\section{CONCLUSIONS}

This study has statistically analysed the influence of work placement on the academic achievements of undergraduate design students. To the authors' knowledge, this is the first time a quantitative study such this has been carried out on design students. This study is not addressing all the issues related to this topic. Rather, it is meant to be a starting point from which other researchers can build upon. The key contribution of this study is that it quantitatively shows, for the first time, the correlation between placement and academic achievement in design undergraduate education. It is the authors' opinion that this initial contribution can enable other researchers to replicate the 
same study in other design universities (and compare results), and/or to carry out qualitative studies to better explore factors behind this correlation. In particular, the research questions addressed in the study and the findings are summarized below:

(i) Do design students who undertake a work placement achieve higher academic performance in their final year?

Results show that students who went on placement achieved a higher final year average $(66.7 \%$ vs $59.6 \%)$. Similar results can be found when classifying students as higher achievers (students who obtained $60 \%$ or more in the second year) and lower achievers ( $68.1 \%$ vs $64.4 \%$ for higher achievers, and $62.2 \%$ vs $56.8 \%$ for lower achievers).

(ii) If yes, is it because they are better than non-placement students or because the placement experience provides an added value to them?

For each group (higher and lower achievers) the average mark improvement from the second year to the final year was compared. The study demonstrates that higher achievers who go on placement are not academically better than non-placement students (66.8\% vs $66.3 \%$ ), and that the placement experience enables them to obtain a higher final year average mark (68.1\% vs $64.4 \%)$. Lower achievers who decide to go on placement are slightly academically better at the end of the second year than nonplacement students $(55.6 \%$ vs $53.4 \%$ ); however results suggest that the placement enables students to achieve significant grade improvement (62.2\% vs $56.8 \%)$.

(iii) If work placement provides an added value to students in terms of academic performance in their final year, is this true for all the modules or only for some particular ones?

The results of this study seem to suggest that the work placement experience give students a particular advantage in the Major project and in the modules characterized by a design-focused assessment components. However, this result must be considered with care because of the reasons outlined in the previous section.

In general, the findings of this study must be taken with a certain degree of caution, as highlighted by the following limitations:

- The data used to calculate the second year average mark are obtained across two different academic years (see Figure 1), meaning that, within each programme, placement and non-placement students attended the same Level 2 modules but in different academic years. For this reason, lectures, learning resources, assessment criteria and assessment modalities may have changed slightly, and this might have had an influence on results. However, as said before, the 
inclusion of four different academic years in the analysis should limit this problem.

- Most of the Level 2 and final year modules have some assessment components based on group work. Therefore it may happen that some groups involve both placement and non-placement students. This might have an influence on the results of this study because it is not possible to fully distinguish and mark the contribution of each student in group assessments, even with the inclusion of an individually marked element. However, the group assignments contribute only a small percentage to the overall module assessment: Contextual Design (25\%), Innovation Management (30\%), and Environmentally Sensitive Design (15\%).

- Finally, even if our results clearly show the correlation between placement and academic achievement, it must be acknowledged that correlation does not necessarily mean causality. As underlined by Gomez et al. (2004), the demonstration of the casual effect of placement on academic performance would require distinguishing between the students who deliberately wanted to take the full time route, the ones who wanted to go on placement but did not succeed in finding a placement opportunity, and the ones who actually went on placement. In fact 'it is possible that those factors that predispose a student to take a placement might be linked to those that determine academic performance' (ibid.). However, regarding demographic factors, a large statistical study conducted on more than 6000 students (Reddy and Moore, 2011) showed that students get consistent academic benefit from placement regardless of ethnicity, gender and socio-economic conditions.

Considering the findings of this study, and their limitations, some directions for future research can be identified:

- This study, in line with that done by Reddy and Moores (2006), differentiated between higher and lower achievers. It would be interesting to further differentiate students in at least three categories (e.g. A, B and C grade band). This would provide information to better investigate the influence of placement on students with different academic abilities. However, this would require a bigger sample population than the one considered in this study, in order to obtain statistically significant information.

- Following the previously mentioned consideration made by Gomez et al. (2004), it would be interesting to analyse the academic achievements of students considering not only if they were placement or non-placement students, but also 
if they chose to take the full time route or if they took it because they were unable to find a placement.

- It would also be important to enlarge the study to other design universities to undertake comparative analysis to understand differences and commonalities.

- Another interesting direction would be to better focus on the individual modules investigating the results within each assessment component. In this way it would be possible to differentiate between design-focused assessments and predominantly theoretical assessments. This would allow to validate or not the initial findings on the positive influence of work placement on design-focused modules.

- It would be also intend interesting investigate the selection process used by employers for placement, to discover whether this process impacts on the student experience and learning whilst on placement.

- Finally, and potentially in combination with other previously mentioned points, it would be important to combine a quantitative analysis with a qualitative one. For example, questionnaires and/or interviews could be used to assess attitudes and perceptions of placement students (before and after the placement), and of nonplacement students. 


\section{References}

Auburn, T. (2007) Identity and placement learning: student accounts of the transition back to university following a placement year. Studies in Higher Education 32(1): 117-33.

Blackwell, A., Bowes, L., Harvey, L., Hesketh, A. and Knight, P.T. (2001) Transforming work experience in higher education. British Educational Research Journal, 27(3): 269-85.

Blasko, Z., Little, B. and Woodley, A. (2002) UK Graduates and the Impact of Work Experience. Higher Education Funding Council for England (HEFCE).

Bullock, K., V. Gould, M. Hejmadi, and G. Lock. (2009) Work placement experience: Should I stay or should I go? Higher Education Research and Development 28:481-494.

Dearing, R. (1997) The National Committee of Inquiry into Higher Education: Higher Education for the 21st Century. London: HMSO.

Department of Business Innovation and Skills (2012) Following up the Wilson review of businessuniversity collaboration. Next steps for universities, business and Government. London: BIS.

Department for Education and Skills' White Paper on Higher Education (2003) The Future of Higher Education. Norwich: HMSO.

Duignan, J (2002) Undergraduate Work Placement and Academic Performance: failing by doing, Conference Proceedings HERDSA Quality Conversations International Conference, 7-10 July 2002, Edith Cowan University, Perth, Western Australia. Available at: http://www.ecu.edu.au/conferences/herdsa/main/ papers/ref/pdf/Duignan.pdf

Duignan, J. (2003) Placement and Adding Value to the Academic Performance of Undergraduates: reconfiguring the architecture - an empirical investigation. Journal of Vocational Education and Training 55(3): 335-350.

Gomez, S., Lush, D. \& Clements, M. (2004) Work placements enhance the academic performance of bioscience undergraduates. Journal of Vocational Education and Training 56(3): 373-386.

Greenbank, P. (2002) Undergraduate work experience: an alternative approach using microbusinesses. Education and Training 44(6): 261-70.

Mandilaras, A. (2004) Industrial placement and degree performance: evidence from a British higher institution, International Review of Education Economics 3(1): 39-51.

Mason, G., Williams, G., Cranmer, S. and Guile, D. (2003) How much does higher education enhance the employability of graduates? Available at: www.hefce.ac.uk/pubs/rdreports/2003/rd13 03/ (accessed 02 July 2014).

Mendez, R. (2008) The correlation between industrial placements and final degree results: A study of engineering placement students. Leicester: Student Learning Centre, University of Leicester.

Morgan, A. (1997) National vocational qualifications in a business studies degree. Journal of Vocational Education and Training 49(2): 181-94. 
Morgan, A. and Turner, D. (2000) Adding value to the work placement: working towards a professional qualification in an undergraduate degree programme. Education \& Training 42(8): 453-60.

Muhamad, S. (2012) Graduate employability and transferable skills: A review. Advances in Natural and Applied Sciences, 6(6): 882-885.

Neill, N. and Mulholland, G. (2003) Student placement - structure, skills and e-support. Education and Training 45(2): 89-99.

Neill, N., Mulholland, G., Ross, V. and Leckey, J. (2004) The influence of part-time work on student placement. Journal of Further and Higher Education 28(2): 123-37.

Little, B. and Harvey, L. (2007) UK work placements: a choice too far? Tertiary Education and Management 13(3): 227-45.

Lucas, U., \& Tang, P.L. (2007) Developing a reflective capacity within undergraduate education: The role of work-based placement learning. Report of a research project funded by the Higher Education Academy and the Institute of Chartered Accountants in England and Wales 20052007. York: The Higher Education Academy.

Patel, N., Brinkman, W.P. and Coughlan, J. (2012) Work placements and academic achievement: undergraduate computing students. Education \& Training 54(6): 523-533.

Rakowski, R.T., (1990) Assessment of student performance during industrial training placements. International Journal of Technology and Design Education 1(2): 106-110.

Rawlings, P., White, P. and Stephens, R., (2005) Practice-based learning in information systems: the advantages for students. Journal of Information Systems Education 16(4): 455-464.

Reddy, P. and Moores, E. (2006) Measuring the benefits of a psychology placement year. Assessment and Evaluation in Higher Education 31(5): 551-67.

Reddy, P. and Moores, E. (2012) Placement year academic benefit revisited: effects of demographics, prior achievement and degree programme. Teaching in Higher Education 17(2): 153-165.

Surridge, I. (2009) Accounting and finance degrees: Is the academic performance of placement students better? Accounting Education 18:471-485.

Walmsley, A., Thomas, R., \& Jameson, S. (2006) Surprise and sense making: Undergraduate placement experiences in SMEs. Education \& Training 18(5): 360-372. 


\section{List of Figures}

Figure 1. The data considered in the analysis comprises students who had graduated in one of the three Brunel Design programmes in the 2010/11, 2011/12, 2012/13 and 2013/14 academic years.

Figure 2. Comparison of final year academic achievements of placement and non-placement students considering the average mark of all modules and the average mark of only the common modules.

Figure 3. Comparison of Level 2 academic achievements of placement and non-placement students.

Figure 4. Comparison of the academic performance improvements (from Level 2 to the final year) of placement and non-placement students.

Figure 5. Comparison of the academic performance improvements (from Level 2 to the final year) of placement and non-placement students, differentiating them in higher achievers (students whose second year average mark was $60 \%$ or above) and lower achievers (students who whose second year average mark was less than 60\%).

Figure 6. Comparison of the academic performance of placement and non-placement students (differentiating them in higher achievers and lower achievers) in four different final year modules. The first three modules are considered predominantly focused on design, while the fourth is considered predominantly theoretical. 